\title{
Methodical Fundamentals for Choosing the Location of Waste Treatment Enterprises Based on the Indicators of the Territorial System Status
}

\author{
Vladimir Gvozdev \\ Technical Cybernetics Department \\ Ufa State Aviation Technical University \\ Ufa, Russia
}

\author{
Olga Khristodulo \\ Geoinformation Systems Department \\ Ufa State Aviation Technical University \\ Ufa, Russia \\ o-hristodulo@mail.ru
}

\author{
Marat Shamsutdinov \\ Geoinformation Systems Department \\ Ufa State Aviation Technical University \\ Ufa, Russia
}

\begin{abstract}
In recent years, effective environmental protection activities of the environment related to anthropogenic pollution, which has become widespread, influenced by increasing industrial production and population growth, have gained particular importance. Waste can be viewed in two different ways: as a powerful trigger of pollution that can lead to an environmental catastrophe and as secondary raw materials for waste recycling enterprises and, as a result, the source of necessary resources for industry and the economy. But at the same time, the established practice of waste management in Russia is characterized by an everincreasing negative impact on the environment and human health and an inefficient use of material and energy resources. At the same time, the need to resolve the issues related to recycling has become more acute in recent years as a result of the deterioration in the quality of natural raw materials and the depletion of its number and the accumulation of volumes and types of waste. This article outlines the main components of municipal solid waste management problems from the perspective of considering the waste management system as an open complex system with ambiguous goals. The systemforming factors of the formation of a geographicallydistributed waste management system are emphasized. The method of selecting the location of industrial waste processing enterprises is proposed depends on various indicators of the state of the territorial system based on mathematical and geographic information modeling. An example of resolving the issues of zoning the territory of the Republic of Bashkortostan by a set of indicators characterizing the impact of waste on the environment and human health
\end{abstract}

Keywords-waste recycling, territorial system indicators, modeling, geographic information systems, evergetics.

\section{RELEVANCE OF INFORMATION SUPPORT FOR SOLID WASTE MANAGEMENT}

Issues related to formation, accumulation, disposal, recycling, and disposal of waste are among the most pressing social problems in the world nowadays. Today, both in Russia and in the Republic of Bashkortostan, in particular, there has been a significant increase in waste generation, which is primarily due to the high rates of socio-economic development of society [1-2].

The primary objective of waste management is the transition from the waste disposal to its reuse. Despite this, over the years, the average usage of waste as secondary raw materials estimates about 3\% of the total annual volume. More than $97 \%$ of the waste produced is delivered to special landfills and dumps, where it is simply getting buried into the ground, thereby getting rid of raw materials suitable for recycling. Only cost-effective and highly liquid waste, such as polymeric materials, waste and scrap of ferrous and nonferrous metals, clean textile, and wood waste is involved in economic circulation.

Consequently, in order for the country not to finally become a huge dump it is necessary to look for effective solutions in the field of waste management. One of the solutions is constructing industrial waste treatment plants.

Thus, the experience of different countries shows that competent recycling can not only free the area from the garbage and preserve natural resources, but also make profits by generating additional electricity at the incineration plants.

Using advanced software and information technology is one of the most promising directions, that has been developed actively in the recent years because of the need to optimize environmental management processes following the automation of certain functions and tasks.

The Ministry of the Environment and Natural Resources of the Republic of Bashkortostan actively uses and develops various information systems in the Republic of Bashkortostan for the effective implementation of state environmental protection activities, the development and implementation of state regulation measures in environmental management and safety, and monitoring [3]

Striving for the integrated use of various information containing not only attribute, but also spatial characteristics, stimulates professionals to apply the best ways of obtaining and analyzing this kind of data for assessing the observed situation. GIS technologies can act as a tool for structuring, visualizing and comparing heterogeneous, geographically oriented data. [4]. These technologies significantly improve the planning of waste management, as they provide an opportunity to analyze the geographical location of municipal solid waste (MSW) landfills, their quantitative and qualitative characteristics. They also help to consider alternative placement options for waste collection and recycling centers in terms of transportation and storage costs, which, ultimately, will allow you to make thorough decisions in the field of waste management.

The use of various methods of system analysis that creates the basis for the analysis of territorial and temporal variability of the state indicators of the territorial systems 
components under uncertainty of the properties of interrelated processes caused by natural, social, man-made factors, including the processes of occurrence, storage, transportation and recycling, is possible as a research methodology for complex systems of different nature [5].

Thus, to solve the issue of information support for the management of MSW in the Republic of Bashkortostan, it is necessary to adapt GIS technologies and systems analysis methods, taking into account the specifics of MSW management problems, which will allow to reasonably answer what is happening in the waste management system, whether the situation improves or not, and to assess whether the choice of the sites is reasonable for constructing enterprises for waste sorting and recycling. One aspect of this issue is the refinement of approaches around the collection and transportation of waste, which will not only optimize routes, and, consequently, the costs of transporting waste, but also find the best places for constructing waste sorting and waste-processing enterprises [6].

\section{COMPREHENSIVE DESCRIPTION OF THE STATE OF MUNICIPALITIES IN DEALING WITH MSW MANAGEMENT TASKS}

The management system of solid municipal waste belongs to the class of open complex systems with ambiguous purposes. The management of MSW involves various concerned parties who have different motives and different personal ontological models of the problem situation caused by the generation, storage, transportation, and processing of waste [7-8]. This makes it necessary to improve the methods of developing consolidated solutions recognized by all concerned parties. This creates the basis for the coordinated activities of various government bodies authorized to solve a complex of issues related to the problem of MSW management.

For example, concerned parties include:

- population;

- municipal and regional bodies;

- government regulators;

- business (transportation companies for MSW, operation of landfills for MSW, processing enterprises, etc.);

- investment funds;

- public environmental organizations;

- expert community (research institutes, universities, etc.).

Waste management has to be carried out not only in terms of fuzzy management goals and different motives of government representatives, business, and the public in resolving the problem situation, but also relating to fundamental and measuring uncertainty, caused by a lack of knowledge about the mechanisms of waste impact on the territorial systems; insufficient knowledge of causal relationships between the state of waste and the state of the environment and public health; limited data and information present in the departmental information systems and one way or another associated with the generation, collection, storage, recycling of waste.

The system-forming factors that enable to allocate a geographically-distributed waste management system include:

- the volume and characteristics of the industrial and household waste generated, stored, and processed at various parts of the territorial system;

- territorial and temporal dynamics of the waste impact on the environment and public health;

- territorial and temporal aspects of collection, storage, transportation, and processing of waste;

- territorial and temporal features of the people's attitude to waste management.

As local control loops in the waste management system, the following should be highlighted:

- management of negative impact on the natural environment and human health

- management of choosing permanent and temporary storage sites for waste, construction sites for waste treatment plants, taking into account the amount of waste produced by different types (industrial, domestic) in storage, as well as the state of the transport network in different parts of the territorial system;

- management of requirements for the activities of enterprises in terms of recycling;

- management of the economic consequences of storing and processing of waste, including the tariffs for the collection, storage, transportation and processing of waste;

- management of values, aspirations, behavior of the population in waste management issues.

The above list is not final; its composition may be adjusted as fundamental and axiological knowledge gained by heterogeneous factors is accumulated in the course of practical activity.

Target groups of clients are associated for each local control loop and management objectives are defined, as well as performance indicators and management efficiency and management quality indicators [9]. Thus, the concerned parties are:

- government agencies that develop sets of legal norms to resolve the situation in the field of waste management;

- businesses that seek to maximize profits from the construction of waste management facilities;

- people who are concerned about the environmental issues and their health.

In addition, each of the selected target groups is characterized by a set of features reflecting their motives, based on which, in particular, representatives of these groups can conclude that it is advisable to choose a place for the 
construction of industrial waste treatment plants (Fig. 1). All data presented in Figure 1 was collected by means of the analysis of the materials presented in official documents of the Ministry of Justice and other executive authorities of Russia in the Republic of Bashkortostan [3, 10], reports of the Ministry of the Environment and Natural Resources of the Republic of Bashkortostan [1], and scientific articles [2, $8,11,12]$. Figure 2 shows the distribution of municipalities of the Republic of Bashkortostan based on a combination of attributes used in combining three target groups: government structures, business, and population.

\section{METHODS OF CHOOSING THE LOCATION OF INDUSTRIAL WASTE PROCESSING ENTERPRISES BY THE STATE INDICATORS OF THE TERRITORIAL SYSTEM}

The developed methodology for selecting the location of industrial waste treatment enterprises is a phased consideration of the following criteria:

- consideration of the geography of the territory;

- multi-aspect analysis of the state of municipalities;

- optimization of traffic flows.

- Results of zoning of the territorial systems on particular status indicators provide a basis for evaluating the effectiveness of a waste management system.

- In general, the classification problem is represented in the form:

- $\varphi(\mathrm{x}, \mathrm{y}) \rightarrow \mathrm{S}(\mathrm{x}, \mathrm{y})$

- Where $\varphi(x, y)$ is the surface topography and $S(x, y)$ is a spatial mosaic, formed by sections of the study area, with each element of the mosaic is associated with a certain class of state territorial system $[8,13]$.

- The basis for the transformation of $\varphi(x, y)$ into $S(x, y)$ is the use of different scales that establish a correspondence between the ranges of values of the relief indexes of characteristics and the classes of state of the territory, that is

- $\quad \alpha_{\mathrm{i}} \leq \varphi(\mathrm{x}, \mathrm{y}) \leq \beta_{\mathrm{i}} \rightarrow \mathrm{C}_{\mathrm{i}}$

- Where $\alpha_{\mathrm{i}}$ and $\beta_{\mathrm{i}}$ are boundaries of the i sub-interval of the classification scale; $C_{i}$ is the $i$ class of the state of the site of the territory.

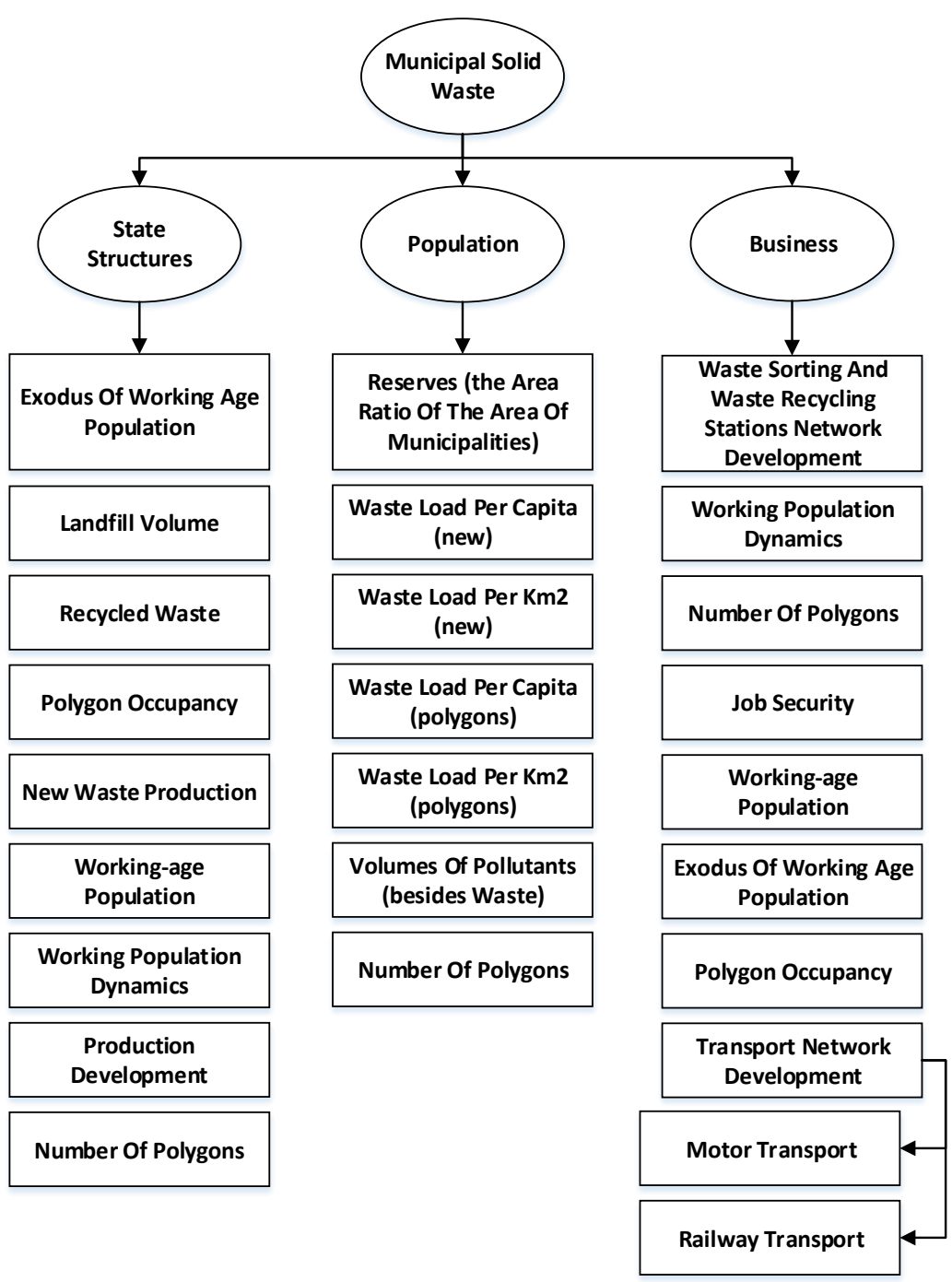

Figure 1. Comprehensive description of the state of municipalities of the Republic of Bashkortostan 


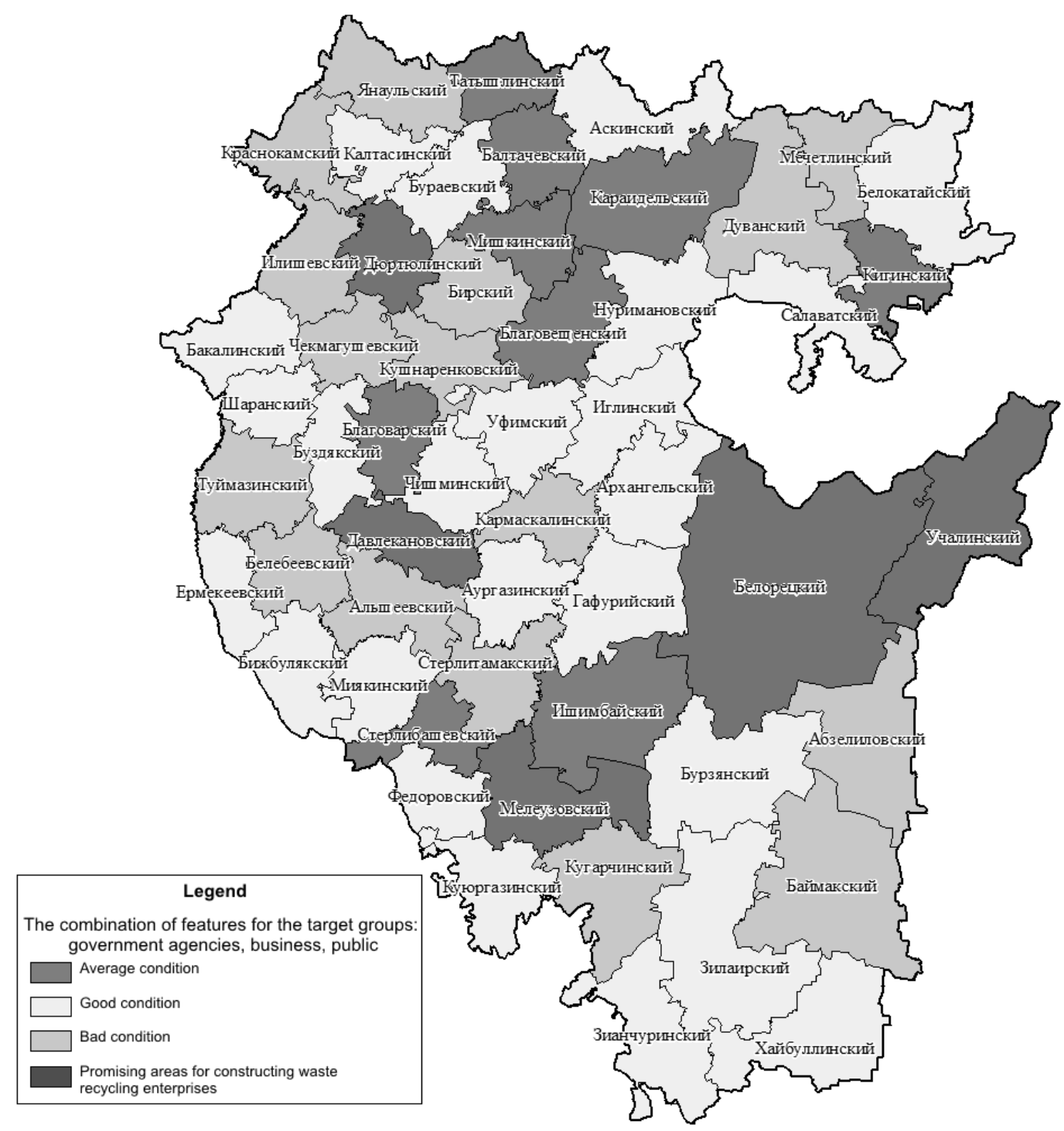

Figure 2. Distribution of municipalities of the Republic of Bashkortostan based on the totality of characteristics used in combining the three target groups

To resolve the problem situation associated with the multi-criteria management of the process of selecting the location of industrial waste processing enterprises, various methods can be used, among which are the apparatus of statistical indices, the ideal point method, and geoinformation technologies. By using these methods, it became possible to assess the Republic of Bashkortostan in terms of waste management, based on zoning of the territory by a set of criteria into the group of regions according to the degree of negative impact on the environment and human health. This will explain the current situation in the field of waste management. The obtained results can be further used as a tool for information support for the development of a negotiated decision on the choice of the location of industrial waste treatment plants.

In solving practical problems related to the assessment of the state of a territorial system, it is rather typical that when only $Z\left(x_{i}, y_{i}\right)=\varphi\left(x_{i}, y_{i}\right),(i=\overline{i ; N})$ are known instead of $\varphi(\mathrm{x}, \mathrm{y})$ corresponding to the nodes of the non-uniform measurement grid. In this case, the model (1) is transformed to the form (3):

$$
\mathrm{Z}\left(\mathrm{x}_{\mathrm{i}}, \mathrm{y}_{\mathrm{i}}\right) \stackrel{\mathrm{P}_{\alpha}}{\rightarrow} \widehat{\mathrm{S}}(\mathrm{x}, \mathrm{y}),(\mathrm{i}=\overline{\mathrm{i} ; \mathrm{N}}),
$$

Where $\hat{S}(x, y)$ is the estimate of $S(x, y)$ depending on $N$, the locations of the measurement grid nodes, and the chosen $P_{\alpha}$ transformation method of the terrain transformation into the spatial mosaic.

When solving applied problems of classification of territorial systems, one often has to deal with a situation where the classification scale is a priori unknown. In this

case, $\hat{P}_{\alpha}$ should strive for actually available sample data.

It is noted in [14] that if $Z\left(x_{i}, y_{i}\right)$ are random variables, the distribution function $\hat{F}(z)$ is an integral characteristic of 


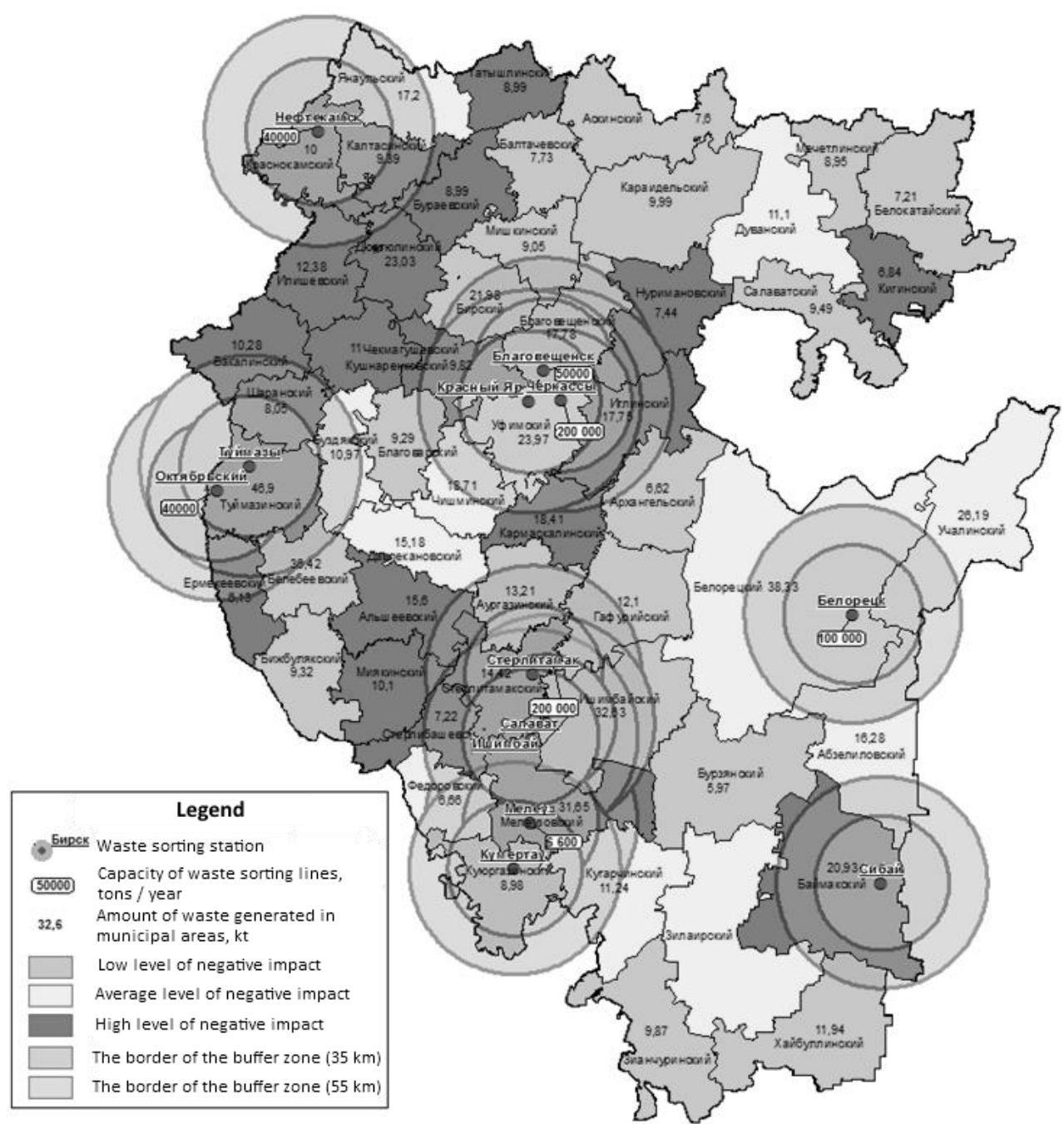

Figure 3. Zoning of the territory of the Republic of Bashkortostan by the generalized indicator for 2015

the statistical relief. In this connection, the classification process should take into account features of evaluation $\hat{F}(z)$, obtained from the values $Z\left(x_{i}, y_{i}\right),(i=\overline{i ; N})$ and the model (3) is transformed to the form (4):

$$
\begin{array}{ccc}
\swarrow & \hat{\mathrm{F}}(\mathrm{z}) & \\
\mathrm{Z}\left(\mathrm{x}_{\mathrm{i}}, \mathrm{y}_{\mathrm{i}}\right) & \rightarrow & \widehat{\mathrm{S}}(\mathrm{x}, \mathrm{y})
\end{array}
$$

From this model it follows that the quality of the mosaic $\hat{S}(x, y)$ is determined by the closer score $\hat{F}(z)$ to the distribution law $F(z)$, which corresponds to sample $Z\left(x_{i}, y_{i}\right)$.

The generalized scheme for classifying areas of the territorial system from the sample data is based on the following:

- All information on the state of the territorial system is contained in the sample data, with the estimate $\hat{F}(z)$ being an exhaustive (regarding the parameter $z$ ) state characteristic;

- The estimation of the spatial mosaic $\hat{S}(x, y)$ is reduced to the division of the territory into areas, each of the areas being related to one of the classes of state. Sites belonging to the same class are assigned the same value of the relief characteristic, by which the integral estimate $F_{\hat{S}}(z)$ can be constructed. Thus, the number of state classes and the boundaries of disjoint classes must be chosen in such a way that the condition (5) is satisfied:

$$
\mathrm{P}_{\mathrm{j}}\left[\hat{\mathrm{F}}(\mathrm{z}), \mathrm{F}_{\widehat{\mathrm{S}}}(\mathrm{z})\right] \rightarrow \min ,
$$

Where $P_{j}$ is $j$ comparison rule for $\hat{F}(z)$ and $F_{\hat{S}}(z)$.

Assuming that the sample values $Z\left(x_{i}, y_{i}\right), i=\overline{i, N}$ are random variables to which the distribution function $\hat{F}(z)$, corresponds, for formalization of the classification scale procedure it is rational to use a grouping approach to statistical data. In [12] various approaches to the construction of $\hat{F}(z)$ estimates from samples of finite (including small) volume are described, as well as different approaches to solving the problem (5). It also describes the engineering methodology that allows to completely formalize the procedure for classifying a territorial system based on homogeneous samples $Z\left(x_{i}, y_{i}\right), i=\overline{i ; N}$. 
Approaches to solving the problem of classifying areas of the territorial system by state indicators should be linked to the management levels: thematic, and operational. In this connection, it is expedient to introduce the concepts of "absolute", "relative" classification scales. The purpose of constructing a "relative" classification scale is to present, in a visual cartographic form, the current (operational) situation, corresponding to the $i$ time slice. In this case, the data, $Z^{(i)}\left(x_{i}, y_{i}\right), i=\overline{i ; N}$, corresponding to the $i$ research conditions, serve as sampling elements.

The goal of constructing an "absolute" classification scale is to create a basis for comparing the state of a territorial system in different time slices.

The absolute scale is formed on the basis of data corresponding to a set of time slices and is designed to compare the states of territories in different time slices $(l=1,2, \cdots, h)$. As sample elements in this case, serves the combined sample (6):

$$
\{\mathrm{z}\}=U_{\mathrm{l}=1}^{\mathrm{h}} \mathrm{Z}^{(\mathrm{l})}\left(\mathrm{x}_{\mathrm{i}}, \mathrm{y}_{\mathrm{i}}\right), \mathrm{i}=\overline{\mathrm{i} ; \mathrm{N}}
$$

Limitations of this approach are the need to observe the conditions of homogeneity of sample data acquired at the nodes of the mesh measurement.

Let's consider a case of choosing the location for industrial waste processing enterprises using the developed waste management information system [4, 11]. The generated waste is characterized by different component composition and, accordingly, different degrees of negative impact, which requires the use of various methods of aggregation of environmental information.

As one of the auxiliary tools that enable zoning of the territory of the Republic of Bashkortostan related to the degree of negative impact, an apparatus of statistical indices can be used. It is based on the compilation of a priori statistical information and the calculation of a single generalized indicator from several particular ones [15].

The results of the annual statistics help estimate the state of the waste management system at various times. But in order to find out how the situation changes in this area, it is necessary to compare information for different years, and for this, different parts of the obtained data must first be compared; that is exactly what statistical indices allow us to do. Consequently, indices are a tool for analyzing state changes over time, as well as a tool for ensuring the comparability of data obtained under different conditions. In addition, the indices are a "powerful" tool that enables you to build an integral indicator of the state of complex objects and ensure the cohesion of indicators obtained under different conditions [16].

The idea of the generalized parameter method $[12,17]$ is that a process characterized by many components is described by a one-dimensional function, the numerical values of which depend on the monitored components of the process. This function is considered as a generic parameter of the process.

When summarizing the parameters that characterize a waste management system, it is necessary to first determine relative values of primary parameters based on statistical indices, and only then build a mathematical expression for the generalized parameter.

Determination of the relative values of particular parameters considered necessary because the state of the object may be characterized by parameters having different dimensions. Therefore, all monitored parameters lead to a single measurement system in which they can be comparable.

In this connection, to calculate statistical indices, one should take a base period and the values of particular parameters that should be translated into the relative (dimensionless) by normalizing the minimum value of this index area:

$$
y_{i, j}(t)=\frac{P_{i}(t)}{P_{i \text { min }}}
$$

Where $\mathrm{P}_{\mathrm{i}}$ is a sign of the municipality; $y_{i, j}$ is a sign of the municipality (private indicator) in relative units.

As a result, each municipality was assigned a relative characteristic of each of its particular characteristics.

The evaluation of the state of the process according to the set of monitored parameters can be estimated using the following generalizing expression:

$$
I_{j}(t)=\frac{\sum y_{i, j}(t)}{N_{j}},
$$

Where $I_{j}(t)$ is generalized process parameter; $\sum y_{i, j}(t)$ is the sum of relative indicators; $N_{j}$ number of private indicators.

As can be seen from the expression, the more $\sum y_{i, j}(t)$ i.e. the value of the private parameter, the greater the contribution it makes to the generalized parameter $I_{j}(t)$. The greater the degree of negative impact of each of the parameters is, the greater the value of the generalized parameter.

Thus, using this formula, a generalized parameter was calculated for each municipal district reflecting the degree of negative impact of waste on the environment and public health. Zoning by using this indicator allowed to divide areas into 3 groups: areas with high, medium, and low levels of negative impact on the environment and human health (Figure 3). In addition, the boundaries of the buffer zones defined by the Program [1] in accordance with the waste collection scheme are highlighted on the map (Figure 3).

By comparing the results of zoning with the existing waste management scheme of the Republic of Bashkortostan, it can be noted that the choice of a site for constructing most industrial waste treatment plants was chosen optimally. Yet in order to proceed to a more detailed assessment of the validity of the choice of locations for waste treatment facilities, it is necessary to use the following analysis-based approaches:

- the degree of negative impact of waste on the environment and public health;

- the possibility of transporting waste without interim storage. 


\section{CONCLUSION}

The issue of choosing a place for constructing waste recycling plants is currently being solved inefficiently as there is no single vision of the problem situation by the concerned parties: the executive authorities of different levels, investors, the area population. Both coinciding and different views of the parties involved in the situation are concerned. This issue should be resolved at the local level, the level of the municipality, taking into account local resources, including the possibility of choosing alternative locations for constructing industrial waste treatment plants, which are subsequently submitted for public discussion. This will significantly reduce social tensions for the population, make profits to investors, and positively affect the environmental situation in the region.

Using geo-information methods for analyzing and summarizing various statistical data enabled mapping the territory of the Republic of Bashkortostan into different areas according to the level of the negative impact on the environment and public health. The map can be used as a tool for informational support to develop a coherent solution for further dialog for all interested parties.

The results of the research presented in the article are partially supported by the grant 18-08-00885 - A "Methodological foundations of multi-criteria management for choosing a location of industrial enterprises for processing waste, based on the provisions of the evergetics."

\section{REFERENCES}

[1] Arpentieva, M.R. "Evergetic strategies and management of community development" / M.R. Arpentiev // Materialy XVII Mezhdunarodnoj konferencii «Problemy upravlenija i modelirovanija v slozhnyh sistemah» 22-25 ijunja 2015 g., Samara [Proceedings of the XVII International Conference Problems of control and simulation of complex systems, 22-25 June 2015, Samara]. - Samara: IPUSS RAN, 2015. - pp.174-180.

[2] "The regional target program for Improvement of the management system of solid household waste in the Republic of Bashkortostan for 2011-2020", approved by a decree of the Government of the Republic of Bashkortostan dated November 18, 2011 No. 412. Ufa, 2011. - 33 p.

[3] Christodoulo O.I. "Development of an information system for the location of technogenic hazards with the use of fuzzy logic" / O.I. Christodoulo, I.F. Salimzyanov, N.R. Gareyeva // «Nauchno-tehnicheskie vedomosti SPbGPU. Informatika. Telekommunikacii. Upravlenie» [Scientific and Technical Journal of St. Petersburg State Polytechnical University. Computer science. Telecommunications. Control"]. - 2015. - No. 5 (229). - pp. 47 - 58.

[4] "State report on the state of natural resources and the environment of the Republic of Bashkortostan in 2017" / Ministry of the Environment and Natural Resources of the Republic of Bashkortostan. - Ufa, 2017. - 330 p.
[5] Khristodulo O., Davletbakova Z., Gvozdev V. "Spatial Information Processing for Decision-making Supporting of Siting Sources of Technogenic Hazards Using Computer Technologies" // 2nd International Conference on Industrial Engineering, Applications and Manufacturing (ICIEAM). - Chelyabinsk, 2017. pp. 15 .

[6] Mikhailov N.I. "Physical and geographical zoning". Moscow: Moscow State University, 1985. - 184 p.

[7] Savoskina R.R., Bahonina E.I. "Analysis of the existing system of management and treatment of municipal solid waste in the Republic of Bashkortostan" / PNRPU Bulletin. Applied ecology. Urbanism. - 2016. - № 1 (21). - pp. 20-39.

[8] Rzevski, G. "Self-Management in the Emerging Global Society" / G. Rzevski // Problemy upravlenija i modelirovanija $\mathrm{v}$ slozhnyh sistemah: Trudy XVII Mezhdunarodnoj konf. (22-25 ijunja 2015 g., Samara, Rossija) [Problems of control and modeling in complex systems: Proceedings of the XVII International Conf. (June 22-25, 2015, Samara, Russia)]. - Samara: SamRC RAS, 2015. - pp. 3-9.

[9] Gvozdev VE, Khristodulo OI, Fakhretdinova E.B. "Information support of waste management on the basis of cognitive, geoinformation and mathematical modelling" // Sbornik nauchnyh trudov Mezhdunarodnoj nauchno-tehnicheskoj konferencii Perspektivnye informacionnye tehnologi [Collection of scientific papers of the International scientific and technical conference Advanced Information Technologies]. - Samara, 2018 - pp. 1110-1114.

[10] 1Raikov A.N. "Convergent management and decision support". - M .: IKAR, 2009. - 244 p.

[11] Ayvazyan SA, Buchstaber VM, Enukov IS, Meshalkin LD "Applied statistics. Classification and reduction of dimensionality". - Moscow: Finance and Statistics, 1989. - $607 \mathrm{p}$.

[12] Gig J. Wang. "Applied general theory of systems". Moscow: Mir, 1981. - Book. 1. - 341 p., Prince. 2 - 730 p.

[13] Vittykh V.A. "Management of situations in complex developing systems using intersubjective theories" // Mehatronika, avtomatizacija, upravlenie [Mechatronics, automation, control]. - 2011. - No. 12. - pp. 2-6.

[14] Kaplan Robert S, Norton David P. "Strategic maps. Transformation of intangible assets into tangible results" / Trans. with English. - M.: Olimp-Business, 2005. - 512 p:

[15] "The territorial scheme of waste management, including municipal solid waste in the Republic of Bashkortostan", approved by the Government of the Republic of Bashkortostan of 03.11.2016 No. 480. Ufa, 2016. - 302 p.

[16] Bahonina E.I., Savoskina R.R. "The situation with municipal solid waste in the Republic of Bashkortostan" // Izv. Samar. Nauch. Centra RAN. 2014. - № 1 (6). - pp. 1689-1694.

[17] Gubanov VA, Zakharov V.V., Kovalenkov A.N. "Introduction to system analysis". - Leningrad: Publishing House of Leningrad State University, 1988. $-232 \mathrm{p}$. 